\title{
Fontes nitrogenadas em rações contendo bagaço de cana-de-açúcar hidrolizado no desempenho de bovinos confinados em terminação
}

[Nitrogen source on performance of feedlot young bulls fed hydrolyzed sugarcane bagasse diets]

\author{
A.V. Pires ${ }^{1}$, R.C. Oliveira Junior ${ }^{2 *}$, I. Susin ${ }^{1}$, J.J.R. Fernandes ${ }^{3}$, J.B. Morais ${ }^{4}$, C.Q. Mendes ${ }^{5}$ \\ ${ }^{1}$ Escola Superior de Agricultura "Luiz de Queiroz" - USP - Piracicaba, SP \\ ${ }^{2}$ Universidade Estadual de Goiás - São Luiz dos Belos Montes, GO \\ ${ }^{3}$ Escola de Veterinária - UFG - Goiânia, GO \\ ${ }^{4}$ Engenheira agrônoma autônoma \\ ${ }^{5}$ Aluno de pós-graduação - ESALQ - USP - Piracicaba, SP
}

\begin{abstract}
RESUMO
Oitenta e um machos não castrados das raças Nelore (27), Canchim (27) e Holandesa (27), com peso médio inicial de 360kg e idade média de 18 meses, foram utilizados para avaliar os efeitos da substituição de fonte de proteína verdadeira (farelo de soja), por nitrogênio não protéico (NNP), uréia ou amiréia (fonte de nitrogênio não protéico de suposta liberação gradativa) sobre o desempenho de bovinos confinados. $\mathrm{O}$ delineamento experimental foi o de blocos inteiramente ao acaso com três animais por baia e nove baias por tratamento. Os blocos foram delineados de acordo com o peso inicial e na raça. As rações experimentais continham BTPV ( $45 \%$ MS da dieta) e BIN ( $5 \%$ MS da dieta) como fontes de volumosos e $50 \%$ de concentrado. Os tratamentos consistiam de: 1) concentrado contendo farelo de soja (FS); 2) concentrado contendo uréia e 3) concentrado contendo amiréia (A-150S). O consumo de matéria seca (CMS) foi de 8,99; 7,43 e 7,69kg/dia, o ganho de peso diário (GPD) foi de 0,983;0,368 e 0,404kg/dia e a conversão alimentar (CA) 9,56; 20,14 e 19,54kg MS/kg de ganho para os tratamentos FS, uréia e A-150S, respectivamente. As rações com FS apresentaram proporcionalmente maior $(\mathrm{P}<0,01) \mathrm{CMS}$ e maior GPD e melhor $\mathrm{CA}$ em relação aos tratamentos uréia e A$150 \mathrm{~S}$. As rações com uréia e A-150S não diferiram $(\mathrm{P}>0,05)$ entre si. A substituição do FS por fontes de NNP reduziu o desempenho de bovino de corte em terminação.
\end{abstract}

Palavras-chave: novilho, amiréia, farelo de soja, uréia, consumo, ganho de peso

\begin{abstract}
Eighty-one young bulls (27 Nellore, 27 Canchim, and 27 Holstein), averaging 18-month-old and weighting $360 \mathrm{~kg}$ of initial body weight $(B W)$, were used to evaluate the effects of nitrogen sources on feedlot performance. Treatments were assigned in a completely randomized block design using three steers per stall and nine per treatment. Blocks were defined by initial $B W$ and breed. Experimental treatments were: 1) soybean meal, 2) urea, and 3) starea. Diets were isonitrogenous and isoenergetic composed by 50\% concentrate and $50 \%$ forage $(45 \%$ hydrolyzed sugarcane bagasse $+5 \%$ in natura sugarcane bagasse). Dry matter intakes (DMI) were 8.99, 7.43, and $7.69 \mathrm{~kg} /$ day, average daily gains (ADG) were 0.983, 0.368, and $0.404 \mathrm{~kg} /$ day and feed efficiencies were $9.56,20.14$, and $19.54 \mathrm{~kg}$ DM/kg of gain for soybean meal, urea and starea treatments, respectively for steers fed. Diets with soybean meal showed proportionally higher $(P<0.01)$ $D M I$, higher average daily gain and better feed efficiency compared to urea and starea diets. No differences $(P>0.05)$ between urea and starea treatments were observed. Replacement of soybean meal by nonprotein nitrogen sources decreased the finishing beef steers performance.
\end{abstract}

Keywords: steer, soybean meal, starea, urea, intake, weight gain

Recebido em 27 de abril de 2007

Aceito em 17 de janeiro de 2008

*Endereço para correspondência (corresponding addres)

Rua 235, Qd 45 LT 36 casa 03, Setor Coimbra - 74535-260 - Goiânia, GO.

E-mail: reinaldo.cunha@ueg.br 


\section{INTRODUÇÃO}

Rações com baixa concentração de energia apresentam menor capacidade de resposta com o uso de nitrogênio não protéico (NNP), podendo não ocorrer sincronismo entre a disponibilidade ruminal de amônia $\left(\mathrm{NH}_{3}\right)$ e energia (Owens e Zinn, 1988). Esse fato poderia ser amenizado mediante uso de fonte de NNP que sofresse hidrólise ruminal mais lenta quando comparada à uréia (ex.: amiréia).

O uso de NNP reduz os custos de suplementação protéica, já que seu valor é menor que o de uma fonte de proteína verdadeira, suprindo a mesma quantidade de nitrogênio. Entretanto, a fonte de NNP mais utilizada é a uréia (Ferreira et al., 2007) que apresenta rápida liberação de amônia no rúmen que, dependendo da quantidade usada, pode exceder a capacidade de utilização dos microrganismos. Conseqüentemente, a amônia em excesso é absorvida pela parede ruminal e pode tornar-se tóxica ao animal, devido à incapacidade do fígado em metabolizá-la. Além disso, a metabolização de amônia em uréia envolve gasto de energia. A uréia circulante poderá ser reciclada, voltando ao rúmen, via parede ruminal e saliva ou ser excretada via urina (Owens e Zinn, 1988).

A utilização de fonte de NNP de liberação lenta de amônia (amiréa) teria as vantagens de aumentar a disponibilidade de nitrogênio (N) para a síntese microbiana e reduzir os riscos com intoxicação (Bartley e Deyoe, 1975).

A amiréia é obtida por processo de extrusão da uréia que consiste na união com a molécula de amido gelatinizado mediante exposição a condições de pressão, temperatura e umidade por determinado tempo. O benefício proposto por essa prática seria o aumento na velocidade de fermentação do amido no rúmen, aliado à redução da velocidade de liberação de amônia oriunda da uréia, compatibilizando os dois fatores para a síntese de proteína microbiana (Silva et al., 1994; Seixas et al., 1999).

Devido ao apelo da indústria sobre as vantagens da amiréia em relação à uréia na redução da toxidez e na melhora do desempenho dos ruminantes, alguns produtores passaram a utilizar aquele produto. $\mathrm{O}$ trabalho realizado por Gonçalves et al (2004) demonstrou efeitos benéficos da amiréia em relação à uréia convencional. Contudo, outros trabalhos (Pires et al., 2004; Oliveira Junior et al., 2006) não apresentaram vantagens da amiréia em relação à uréia, sugerindo mais estudos para melhor conhecimento da amiréia.

O bagaço tratado sob pressão e vapor (BTPV), quando utilizado em rações para bovinos em confinamento, tem proporcionado desempenhos satisfatórios (Lanna e Boin, 1990; Nussio, 1993; Rabelo, 2002). No entanto, para se ter condições ruminais adequadas, é necessária a adição de fonte de fibra íntegra, como o bagaço in natura (BIN) (Nussio, 1993; Rabelo, 2002) ou a ponta de cana picada (Hausknecht, 1996).

O objetivo deste trabalho foi comparar a substituição de proteína verdadeira (farelo de soja) por uréia ou amiréia (fonte de NNP de suposta liberação lenta) no desempenho de bovinos confinados em terminação, tendo o BTPV como principal volumoso ( $45 \%$ da MS).

\section{MATERIAL E MÉTODOS}

Foram utilizados 81 novilhos não castrados, 27 da raça Nelore, 27 da Canchim e 27 da Holandesa, com peso médio inicial de $360 \mathrm{~kg}$ e 18 meses de idade, em média. Os animais, alojados em baias cobertas, com piso, cocho e bebedouro de concreto, e distribuídos em 27 baias, com três animais por baia, foram previamente everminados e receberam dose de complexo vitamínico ADE na fase de adaptação às rações e às instalações.

As rações experimentais continham BTPV (45\% MS da dieta) e BIN (5\% MS da dieta) como fontes de volumosos e $50 \%$ de concentrado. Os tratamentos foram estabelecidos pela substituição da fonte de proteína verdadeira (farelo de soja FS), por uréia ou amiréia (A-150S). As fontes de NNP utilizadas foram: uréia agrícola e uréia convencional extrusada, utilizando-se o milho como fonte de amido ${ }^{1}$. As rações isoenergéticas e isonitrogenadas foram formuladas segundo $o$ NRC (Nutrient..., 1996) de bovinos de corte (Tab. 1).

${ }^{1}$ Amiréia $150 \mathrm{~S}^{\circledR}$, Pajoara Indústria e Comércio - Campo Grande, MS - Brasil. 
Fontes nitrogenadas em rações...

Tabela 1. Proporção dos ingredientes e composição química das dietas (\% da MS)

\begin{tabular}{|c|c|c|c|}
\hline \multirow{2}{*}{ Ingrediente } & \multicolumn{3}{|c|}{ Tratamento } \\
\hline & FS & Uréia & A-150S \\
\hline Bagaço hidrolisado (BTPV) & 45,0 & 45,0 & 45,0 \\
\hline Bagaço in natura & 5,0 & 5,0 & 5,0 \\
\hline Milho moído & 19,0 & 20,0 & 20,0 \\
\hline Polpa cítrica & 13,0 & 24,0 & 22,2 \\
\hline Farelo de soja (FS) & 17,0 & 3,0 & 3,0 \\
\hline Uréia & - & 2,0 & - \\
\hline Amiréia 150S (A-150S) & - & - & 3,7 \\
\hline Mistura mineral $^{1}$ & 0,93 & 0,68 & 0,80 \\
\hline Monoamônio fosfato & 0,07 & 0,32 & 0,30 \\
\hline \multicolumn{4}{|l|}{ Composição química } \\
\hline MS (\% da matéria natural) & 62,4 & 63,9 & 62,1 \\
\hline Proteína bruta & 11,8 & 11,3 & 11,4 \\
\hline Fibra em detergente neutro & 39,3 & 38,4 & 39,2 \\
\hline Fibra em detergente ácido & 35,6 & 36,7 & 36,8 \\
\hline Matéria mineral & 5,8 & 5,4 & 5,8 \\
\hline Extrato etéreo & 1,9 & 2,0 & 1,9 \\
\hline Nutrientes digestíveis totais ${ }^{2}$ & 59,0 & 57,7 & 57,7 \\
\hline \multicolumn{4}{|c|}{$\begin{array}{l}{ }^{1} \text { Composição no tratamento } \mathrm{FS}: \mathrm{NNP}=1,74 \% ; \mathrm{Ca}=0,12 \% ; \mathrm{P}=4 \% ; \mathrm{S}=2,7 \% ; \mathrm{Cu}=750 \mathrm{ppm} ; \mathrm{I}=40 \mathrm{ppm} ; \mathrm{Mn}=1500 \mathrm{ppm} \text {; } \\
\mathrm{Se}=10 \text { ppm; } \mathrm{Zn}=2250 \mathrm{ppm} ; \text { vit.A=300000UI/kg; vit.D3=20000UI/kg; Vit.E=3500UI/kg; Rumensin=2\%. Composição nos } \\
\text { tratamentos uréia e A-150S: NNP=4,35\%; } \mathrm{Ca}=0,12 \% ; \mathrm{P}=10 \% ; \mathrm{S}=7,1 \% ; \mathrm{Mg}=2,0 \% ; \mathrm{Cu}=750 \mathrm{ppm} ; \mathrm{I}=40 \mathrm{ppm} ; \mathrm{Mn}=1500 \\
\text { ppm; Se=10 ppm; } \mathrm{Zn}=2250 \text { ppm; vit.A=300000 UI/kg; vit.D3=20000 UI } / \mathrm{kg} ; \mathrm{Vit} . \mathrm{E}=3500 \mathrm{UI} / \mathrm{kg} ; \text { Rumensin=2\%. } \\
{ }^{2} \text { Segundo o NRC (Nutrient..., 1996). }\end{array}$} \\
\hline
\end{tabular}

O período experimental teve duração de 98 dias, sendo os primeiros 14 dias destinados à adaptação dos animais às instalações e rações experimentais, e o restante do período segmentado em três subperíodos de 28 dias cada um. Os animais foram pesados no final do período de adaptação e no final de cada subperíodo experimental, após jejum alimentar de 16 horas.

Os dados de consumo de matéria seca (CMS) por animal/dia foram obtidos calculando-se a diferença entre a quantidade de MS fornecida e a de sobra. A quantidade de alimento fornecida foi determinada diariamente com a utilização de balança eletrônica do vagão para ração completa, ajustado diariamente com base nas sobras do dia anterior, mantendo as sobras abaixo de 5\%.

Semanalmente, foram retiradas amostras dos alimentos oferecidos e das sobras, os quais foram compostos por subperíodo e tratamento. As amostras foram conservadas a $-10^{\circ} \mathrm{C}$ até serem descongeladas, secas em estufas com ventilação forçada $\left(55^{\circ} \mathrm{C}\right)$ por 72 horas e moídas em moinhos tipo $\mathrm{Wiley}^{2}$ primeiramente em peneira com crivo de $2 \mathrm{~mm}$ e posteriormente em peneiras de $1 \mathrm{~mm}$. Após desidratação por 12 horas a $105^{\circ} \mathrm{C}$ determinaram-se: MS de acordo com Silva (1990); matéria mineral (MM), extrato etéreo (EE) e proteína bruta (PB) de acordo com AOAC (Official..., 1990); fibra insolúvel em detergente neutro (FDN) e fibra insolúvel em detergente ácido (FDA) de acordo com o método de Van Soest et al. (1991), não seqüencial, utilizando $\alpha$ amilase e sulfito de sódio nas determinações de FDN.

Os animais foram distribuídos em delineamento de blocos inteiramente ao acaso de acordo com o peso corporal e raça (peso inicial), em esquema fatorial $3 \times 3$ (3 dietas e 3 raças), com três animais por baia e nove baias por dieta. Os dados foram analisados pelo método dos quadrados mínimos segundo o procedimento LSMEANS do programa computacional SAS (User's..., 1996).

\section{RESULTADOS E DISCUSSÃO}

Os dados de peso vivo dos animais, consumo, ganho de peso e conversão alimentar estão apresentados na Tab. 2.

${ }^{2}$ Marconi - Piracicaba, SP - Brasil. 
Tabela 2. Desempenho de bovinos de corte confinados suplementados com fontes nitrogenadas

\begin{tabular}{|c|c|c|c|c|c|}
\hline \multirow{2}{*}{ Variáveis $^{2}$} & \multicolumn{3}{|c|}{ Tratamentos $^{1}$} & \multirow{2}{*}{$\mathrm{EPM}^{3}$} & \multirow{2}{*}{$\mathrm{P}^{4}$} \\
\hline & FS & Uréia & A-150S & & \\
\hline Peso vivo inicial, $\mathrm{kg}$ & 360,8 & 362,1 & 360,5 & 9,17 & 0,9621 \\
\hline Peso vivo final, $\mathrm{kg}$ & $443,2 \mathrm{a}$ & $392,8 b$ & $394,5 b$ & 10,17 & 0,0001 \\
\hline CMS, kg/d & $9,03 \mathrm{a}$ & $7,29 b$ & $7,65 b$ & 0,16 & 0,0001 \\
\hline$\% \mathrm{PV}$ & $2,21 \mathrm{a}$ & $1,97 \mathrm{~b}$ & $2,04 \mathrm{~b}$ & 0,07 & 0,0002 \\
\hline $\mathrm{g} / \mathrm{kgPV}^{0,75}$ & $98,9 \mathrm{a}$ & $88,0 \mathrm{~b}$ & $90,4 b$ & 2,41 & 0,0001 \\
\hline $\mathrm{GPD}, \mathrm{kg} / \mathrm{d}$ & $0,982 \mathrm{a}$ & $0,376 b$ & $0,412 b$ & 0,06 & 0,0001 \\
\hline $\mathrm{CA}, \mathrm{kg} \mathrm{MS} / \mathrm{kg}$ ganho & $9,50 \mathrm{~b}$ & $19,01 \mathrm{a}$ & $18,52 \mathrm{a}$ & 1,43 & 0,0001 \\
\hline
\end{tabular}

Letras diferentes nas linhas referem-se às médias que diferem entre si pelo teste Tukey $(\mathrm{P}<0,05)$; as médias foram ajustadas pelos quadrados mínimos (LSMEANS);

${ }^{1} \mathrm{FS}=$ farelo de soja; A-150S=amiréia;

${ }^{2} \mathrm{GPD}=$ ganho de peso diário; $\mathrm{CMS}=$ consumo de matéria seca; $\mathrm{CA}=$ conversão alimentar;

${ }^{3}$ Erro Padrão da Média;

${ }^{4} \mathrm{P}=$ Probabilidade de haver efeito significativo entre tratamentos (rações).

Não houve diferenças $(\mathrm{P}>0,05)$ de CMS, GPD e $\mathrm{CA}$ entre os tratamentos contendo uréia ou amiréia, contudo, o tratamento FS apresentou maior CMS, GPD $(\mathrm{P}<0,05)$ e melhor CA $(\mathrm{P}<0,05)$, em relação aos tratamentos que usaram as fontes de NNP. Não houve efeito da interação dieta e raça.

Resultados semelhantes foram observados por Schmidt et al. (1973) ao verificarem maior GPD para o tratamento FS comparado ao tratamento com amiréia. Estes resultados diferem da maioria dos apresentados na literatura (Thompson et al., 1972; Pires et al., 2004), que não verificaram alterações no GPD entre farelo de soja, uréia e amiréia como fonte de $\mathrm{N}$.

Bartley e Deyoe (1975) sumarizaram diversos trabalhos totalizando 12 comparações de GPD e CA de novilhos em terminação que receberam uréia ou amiréia. Esses autores não observaram diferenças nessas comparações, sendo que as médias de todas as comparações de GPD foram iguais $\quad\left(1,25 \mathrm{~kg}\right.$.animal $\left.{ }^{-1} \cdot \mathrm{d}^{-1}\right), \quad$ resultados confirmados por este experimento.

Trabalhos têm sugerido que a substituição total de proteína verdadeira por NNP (uréia) pode resultar em redução na produção microbiana e na digestão, devido às limitações impostas ao crescimento microbiano, ocasionado por falta de peptídeos, aminoácidos e ácidos graxos voláteis de cadeira ramificada (Redman et al., 1980; Tedechi et al., 2000). Neste experimento, essa substituição foi quase total (Tab. 1), o que resultou em desempenhos mais baixos verificados nos tratamentos em que o NNP substituiu o FS.

$\mathrm{O}$ não sincronismo entre a liberação de $\mathrm{N}$ e carboidratos, associado ao consumo insuficiente de proteína não degradável no rúmen (PNDR), são os dois fatores mais limitantes ao desempenho animal quando se utilizam rações ricas em NNP (Nutrient... 1996). Os tratamentos uréia e amiréia apresentaram quantidades reduzidas de carboidratos rapidamente fermentescíveis (Tab. 1) e, provavelmente, PNDR mais baixa, o que pode ter promovido a redução no desempenho segundo o NRC (Nutrient..., 1996). A proteína do farelo de soja apresenta considerável fração de PNDR, contribuindo para o "pool” de proteína metabolizável, o que pode ter proporcionado ganhos mais elevados para os animais do tratamento FS.

Os valores de FDN e FDA foram relativamente altos (Tab. 1), porém, o BTPV possui baixa efetividade da fibra (Castro, 1989; Fox et al., 2000) e o BIN apresenta maior efetividade da fibra (Fox et al., 2000). Assim, a quantidade de BIN na dieta $(5 \%)$ pode não ter sido suficiente para proporcionar ambiente ruminal estável. Entretanto, propiciou ganho de peso razoável no tratamento com FS, uma vez que tem maior quantidade de proteína verdadeira (Tab. 1) e, conseqüentemente, mais proteína metabolizável, o que proporciona maior ganho de peso (Tedeschi et al., 2000).

A falta de fibra efetiva na dieta, diminui-se a atividade de mastigação e, por conseguinte, a 
secreção de saliva e seus tamponantes (bicarbonato e fosfato), que neutralizam os ácidos produzidos pela fermentação da matéria orgânica no rúmen. $\mathrm{O}$ balanço entre os ácidos produzidos na fermentação e a secreção de tamponantes são os maiores fatores determinantes do $\mathrm{pH}$ ruminal. Baixos valores de $\mathrm{pH}$ podem acarretar redução no $\mathrm{CMS}$, baixa digestibilidade da fibra e da produção microbiana (Allen, 1997).

A inclusão de cana picada melhorou o CMS, o GPD e a CA em relação à inclusão do BIN $(\mathrm{P}<0,05)$, em rações contendo como volumoso principal o BTPV (Hausknecht, 1996), demonstrando que, em algumas situações, o BIN não consegue proporcionar ambiente ruminal estável.

Russell et al. (1992) sugeriram que, quando a FDN oriunda da forragem é menor que $20 \%$ da MS, o crescimento microbiano é reduzido em $2,5 \%$ para cada $1 \%$ de redução na FDN daquele valor. Esse ajuste foi incorporado pelo NRC (Nutrient..., 1996) e pelo CNCPS (Fox et al., 2000). No entanto, Armentano e Pereira (1997) demonstraram que a utilização da FDN para expressar a efetividade da fibra dos alimentos é problemática em duas classes de alimentos: forragens processadas em diferentes formas físicas e subprodutos com alto teor de fibra. Os volumosos do atual experimento estão dentro dessas classes de alimentos. Allen (1996) sugeriu aumentar a FDN (\% da MS) da dieta quando incluir subprodutos.

O BTPV apresenta elevada acidez, tamanho reduzido de partícula e alta friabilidade, o que proporciona baixa atividade de ruminação e resulta em baixa produção de saliva (Castro, 1989). Além disso, a presença de carboidratos solúveis prontamente fermentescíveis no BTPV, que são rapidamente degradados no rúmen, produzem grandes quantidades de ácidos graxos voláteis (AGV) que fazem com que o $\mathrm{pH}$ decresça, prejudicando o crescimento microbiano (Lanna e Boin, 1990) e a degradação eficiente da fração fibrosa (Castro, 1989).

Caielli et al. (1997), ao utilizarem BTPV com vários procedimentos de obtenção e dois teores de inclusão (30 e 50\% da MS) em rações de bovinos em confinamento, concluíram que fatores erráticos no processo de obtenção do
BTPV, tais como tempo de permanência no cozedor, controle da temperatura, umidade inicial do bagaço, lavagem do material solúvel, etc. podem afetar sua qualidade assim como o processo de digestão, influenciando o consumo, particularmente quando sua proporção na rações é acima de $40 \%$ da MS. No atual experimento, o BTPV representava 45\% da MS da dieta (Tab.1).

O CMS $\left(98,9 \mathrm{~g} / \mathrm{kg} \mathrm{PV}^{0,75}\right)$, o GPD $(0,982 \mathrm{~kg} / \mathrm{d})$ e a CA (9,50kg MS/kg de ganho) dos animais suplementados com farelo de soja (Tab. 2) estão próximos dos observados por outros autores (Lanna e Boin, 1990; Nussio, 1993; Rabelo, 2002). Em confinamentos comerciais que utilizaram o BTPV, a CA observada foi de 9,3 a 21,6, com média de 12,6 (Nussio, 1993), o que abrange os valores observados nos tratamentos com uréia e amiréia $(19,01$ e $18,52 \mathrm{~kg} \mathrm{MS} / \mathrm{kg}$ de ganho, respectivamente) do atual experimento.

Nussio (1993), ao utilizar 50\% de BTPV e 5\% de BIN, e Rabelo (2002), ao usar 45\% de BTPV e $5 \%$ de BIN, verificaram ganhos mais elevados que os observados nos tratamentos com NNP (uréia e amiréia) e próximos aos do tratamento com farelo de soja. Isso se deve, provavelmente, à fonte de proteína verdadeira (mais de $10 \%$ da MS) usada por esses autores, que não empregaram o NNP como a principal fonte nitrogenada, como utilizado no presente experimento. Isso sugere que os tratamentos com NNP (uréia e amiréia) estavam deficientes em proteína metabolizável, devido à provável redução na síntese de proteína microbiana em decorrência do desbalanço entre energia disponível e proteína verdadeira pois esses tratamentos apresentavam provável baixa PNDR e dependiam, principalmente, da proteína microbiana.

\section{CONCLUSÕES}

A substituição de farelo de soja por fontes de nitrogênio não protéico (uréia ou amiréia), em dietas contendo $45 \%$ de BTPV e $5 \%$ de BIN como volumoso, reduz o desempenho de bovinos na fase de terminação. A amiréia utilizada neste trabalho não apresentou vantagens em relação à uréia quanto ao consumo de matéria seca, ganho de peso diário e conversão alimentar em animais confinados na fase de terminação. 


\section{REFERÊNCIAS BIBLIOGRÁFICAS}

ALLEN, M.S. Fiber requirements for dairy cattle? How low can you go? In: CALIFORNIA NUTRITION CONFERENCE, 1996. Davis. Proceedings... Davis: University of California, 1996. p.12-18.

ALLEN, M.S. Relationship between fermentation and acid production in the rumen and requirement for physically effective fiber. J. Dairy Sci., v.80, p.1447-1462, 1997.

ARMENTANO, L.E.; PEREIRA, M.N. Measuring the effectiveness of fiber by animal response trials. J. Dairy Sci., v.80, p.1416-1425, 1997.

BARTLEY, E.E.; DEYOE, C.W. Starea as a protein replacer for ruminants - review of 10 years of research. Feedstuffs, v.47, p.42-44, 1975

CAIELLI, E.D.; BRAUN, G.; POSSENTI, R.A. Bagaço de cana tratado por explosão à vapor em rações de bovinos em confinamento. Bol. Ind. Anim., v.54, p.33-38, 1997.

CASTRO, F.B. Avaliação do processo de digestão do bagaço de cana-de-açúcar (Saccharum sp. L) auto-hidrolizado em bovinos. 1989. 123f. Dissertação (Mestrado) - Escola Superior de Agricultura "Luiz de Queiroz", Universidade de São Paulo, Piracicaba, SP.

FERREIRA, D.A.; GONÇALVES, L.C.; MOLINA, L.R. et al. Características de fermentação da silagem de cana-deaçúcar tratada com uréia, zeólita, inoculante bacteriano e inoculante/enzimático. Arq. Bras. Med. Vet. Zootec., v.59, p.423-433, 2007.

FOX, D.G.; TYLUTKI, T.P.; VAN AMBURGH, M.E. et al The net carbohydrate and protein system for evaluating herd nutrition and nutrient excretion. Model Documentation. Ithaca, NY: Cornell University, 2000. 235p

GONÇALVES, C.C.M.; TEIXEIRA, J.C.; EVANGELISTA, A.R. et al. Desempenho de bovinos de corte no pasto suplementados com misturas múltiplas contendo uréia e amiréia. Cien. Agrotecnol., v.28, p.174-181, 2004.

HAUSKNECHT, J.C.O.V. Efeito da fonte de fibra e do processamento físico do sorgo sobre o desempenho, digestibilidade e parâmetros ruminais de bovinos alimentados com rações à base de bagaço tratado sob pressão e vapor. 1996. 86f. Dissertação (Mestrado) - Escola Superior de Agricultura "Luiz de Queiroz", Universidade de São Paulo, Piracicaba, SP.

LANNA, D.P.D.; BOIN, C. Efeito de bicarbonato de sódio, feno $\mathrm{e}$ bagaço in natura sobre a digestibilidade $\mathrm{e} o$ desempenho de zebuínos em crescimentos alimentados com bagaço de cana auto-hidrolizado. Anais Esc. Sup. Agric. “Luiz de Queiroz”, v.47, p.417-434, 1990.

NUSSIO, L.G. Efeitos de niveis de concentrado sobre o desempenho de bovinos e a digestibilidade de dietas à base de bagaço de cana-de-açúcar (Saccharum sp. L) tratado sobre pressão e vapor. 1993. 147f. Dissertação (Mestrado) Escola Superior de Agricultura "Luiz de Queiroz", Universidade de São Paulo, Piracicaba, SP.

NUTRIENT requirements of beef cattle. 7.ed. Washington: National Academy, 1996

OFFICIAL methods of analysis. 15.ed. Arlington: AOAC, 1990. v.1, 1117p.
OLIVEIRA JUNIOR, R.C.; PIRES, A.V.; FERNANDES, J.J.R. et al. Efeitos de fontes nitrogenadas, em dietas com alto teor de concentrado para bovinos de corte, sobre o consumo de matéria seca, digestibilidade e degradabilidade dos nutrientes. Cien. Anim. Bras., v.7, p.207-216, 2006.

OWENS, F.N.; ZINN, R. Protein metabolism of ruminant animal. In: $\mathrm{CHURCH}$, D.C. (Ed.). The ruminant animal: digestive physiology and nutrition. Englewood Cliffs: Simon \& Schuster, 1988. p.227-249.

PIRES, A.V.; OLIVEIRA JUNIOR, R.C.; FERNANDES, J.J.R. et al. Substituição do farelo de soja por uréia ou amiréia na dieta de bovinos de corte confinados. Pesq. Agropecu. Bras., v.39, p.937-942, 2004.

RABELO, M.M.A. Efeitos de fontes e níveis de fibra integra, em dietas contendo bagaço de cana-de-açúcar tratado sob pressão e vapor, sobre a digestibilidade, desempenho $e$ comportamento ingestivo de bovinos de corte. 2002. 61f. Dissertação (Mestrado) - Escola Superior de Agricultura "Luiz de Queiroz", Universidade de São Paulo, Piracicaba, SP.

REDMAN, R.G.R.; KELLAWAY, R.C.; LEIBHOLZ, J. Utilization of low quality roughages: Effects of urea and protein supplements of differing solubilities on digesta flow, intake and growth rate of cattle eating oaten chaff. $B r . J$. Nutr., v.44, p.343-354. 1980.

RUSSEL, J.B.; O`CONNOR, J.D.; FOX, D.G. et al. A net carbohydrate and protein system for evaluating cattle diets: I. Ruminal fermentation. J. Anim. Sci., v.70, p.3551-3561, 1992

SCHMIDT, S.P.; JORGENSE, N.A.; BENEVENG, N.J. et al. Comparison of soybean-meal, formaldehyde treated soybeanmeal, urea and starea for steers. J. Anim. Sci., v.37, p.12331237,1973

SEIXAS, J.R.C.; EZEQUIEL, J.M.B.; ARAÚJO, W.D. et al. Desempenho de bovinos confinados alimentados com dietas à base de farelo de algodão, uréia ou amiréia. Rev. Bras. Zootec., v.28, p.432-438, 1999.

SILVA, D.J. Análise de alimentos: métodos químicos e biológicos. Viçosa: UFV, 1990. 166p.

SILVA, J.F.C; PEREIRA, J.C.; VALADARES FILHO, S.C. et al. Valor nutritivo da palha de arroz suplementada com amiréia, fubá+uréia e farelo de soja. Pesq. Agropecu. Bras., v.29, p.1475-14881, 1994.

TEDESCHI, L.O.; FOX, D.G.; RUSSELL, J.B. Accounting for the effects of a ruminal nitrogen deficiency within the structure of the Cornell net carbohydrate and protein SYSTEM. J. Anim. Sci., v.78, p.1648-1658, 2000.

THOMPSON, L.H.; WISE, M.B.; BARRICK, E.R. et al. Starea, urea and sulfur in beef cattle rations. J. Anim. Sci., v.35, p.474-480, 1972.

USER'S guide: statistical analysis system. Release 6.11 . Cary: SAS Institute, 1996.

VAN SOEST, P.J.; ROBERTSON, J.B.; LEWIS, B.A. Methods for dietary fiber, neutral detergent fiber, and nonstarch polysaccharides in relation to animal nutrition. $J$. Dairy Sci., v.74, p.3583-3597, 1991. 